\title{
Os Vínculos Afetivos no Contexto de Acolhimento Institucional: Um Estudo de Campo
}

\author{
Suziani de Cássia Almeida Lemos ${ }^{1}$ \\ Instituto Luterano de Ensino Superior ILES/ULBRA \\ Hanna Hellena Lucavei Gechele \\ Janete Vaz de Andrade \\ Faculdade Guairacá-PR
}

\begin{abstract}
RESUMO - Este trabalho relata uma pesquisa de campo qualitativa que teve como objetivo estudar os vínculos afetivos no contexto de acolhimento institucional. Participaram do estudo quatro mães sociais, 31 crianças e cinco adolescentes. Foi realizada, com cada mãe social, uma entrevista semiestruturada e, em cada casa lar, três observações participantes. Os dados foram analisados mediante a técnica da Análise Temática, sendo especificadas duas categorias de análise. O trabalho evidenciou aspectos que podem dificultar o estabelecimento de vínculos afetivos: escassez de atividades que estimulem a interação, excesso de atividades domésticas e a falta de preparação das mães sociais para o exercício da função. No entanto, apesar das dificuldades encontradas, o estudo mostrou que é possível a formação de vínculos afetivos nesse contexto.
\end{abstract}

Palavras-chave: acolhimento institucional, vínculos afetivos, mães sociais

\section{Affectional Bond in the Context of Institutional Care: A Field Study}

\begin{abstract}
This paper reports a qualitative field research which aimed to study the affectional bond in the context of institutional reception. Four social mothers, 31 children and five adolescents participated in the study. A semistructured interview was carried out with each social mother and, in each house, three participant observations. The data were analyzed using the Thematic Analysis technique, with two categories of analysis being specified. The work revealed aspects that may make it difficult to establish affectional bond: a lack of activities that stimulate interaction, excess of domestic activities and the lack of preparation of the social mothers for the exercise of the function. However, despite the difficulties encountered, the study showed that it is possible to form affectional bond in this context.
\end{abstract}

Keywords: institutional care, emotional ties, social mothers

A institucionalização de crianças tem passado por várias transformações ao longo do tempo. Um acontecimento importante e relativamente recente foi a criação do Estatuto da Criança e do Adolescente (ECA), no ano de 1990, a partir do qual foi percebida a necessidade de reformulação nas formas de acolhimento institucional vigentes. Os antigos orfanatos, que abrigavam grande número de crianças em um mesmo ambiente, foram sendo gradativamente substituídos pelas chamadas casas lares.

De acordo com Silva e Aquino (2005), as casas lares são unidades residenciais de acolhimento para crianças e adolescentes que, por motivos envolvendo maus tratos, violência e abandono, foram afastadas temporariamente do convívio familiar. Essas instituições são responsáveis por garantir a integridade física e emocional das crianças e adolescentes que tiveram, de alguma forma, seus direitos violados. Em suma, é uma proteção especial garantida pelo Estado e prevista no Estatuto da Criança e do Adolescente. Nessas unidades, as crianças e adolescentes permanecem aguardando a decisão judicial em relação ao

1 Endereço para correspondência: Av. JK, 1015, Apto 402, Bloco E, Jardim América, Itumbiara, GO, Brasil. CEP 75.523.425. E-mail. suzianilemos@gmail.com seu retorno à família biológica ou, caso isso não ocorra, ao encaminhamento para adoção.

A estruturação física das casas lares deve ser a mais próxima possível a de uma casa comum, com sala, cozinha, banheiros e quartos (Schogor, 2003). Cada casa lar conta com uma mãe social, pessoa responsável pelo cuidado das crianças e adolescentes acolhidos. Em muitos casos, essas mães sociais residem na casa lar com o esposo e os filhos biológicos.

A função mãe social foi estabelecida pela lei $n^{0} 7.644$ de 1987, que garante os direitos de remuneração de valor não inferior ao salário mínimo, além de outros direitos como décimo terceiro, férias e 24 horas semanais de descanso. O art. $4^{\circ}$ determina as atribuições dessa profissional:

Propiciar o surgimento de condições próprias de uma família, orientando e assistindo os menores colocados sob seus cuidados; administrar o lar, realizando e organizando as tarefas a ela pertinentes; dedicar-se, com exclusividade, aos menores e a casa lar que lhes forem confiados.

De acordo com a referida lei, caberá à mãe social oferecer proteção, carinho, segurança, cuidados físicos e emocionais, entre outros aspectos constituintes dessa relação. A partir da delimitação do ambiente em que a pesquisa foi realizada, faz-se necessário discorrer brevemente sobre o caráter temporário do acolhimento institucional e explorar 
os impasses dessa relação que a mãe social estabelece com as crianças e adolescentes acolhidos.

\section{O Caráter Temporário do Acolhimento Institucional}

Com o surgimento do Estatuto da Criança e do Adolescente (ECA), ocorreram claros avanços no que diz respeito à criança e ao adolescente, um deles é o pleno direito à convivência familiar e comunitária, sendo um dos direitos básicos de todo ser humano. Em seu art. $4^{\circ}$, o ECA garante a proteção integral à criança e ao adolescente, por meio da família, da sociedade e do poder público. No caso de ruptura dos vínculos familiares, o Estado é o responsável pela proteção das crianças e dos adolescentes, sendo estabelecida, pelo estatuto, a excepcionalidade e a provisoriedade do acolhimento institucional.

Conforme Ferreira, Francischini e Patiño (2008), no acolhimento em regime de abrigo, é necessário que se assegure a "preservação dos vínculos familiares e a integração em família substituta quando esgotados os recursos de manutenção na família de origem" (p. 131). A lei 12.010 de 2009 dispõe, em seu artigo $1^{\circ}$, sobre o aperfeiçoamento da sistemática prevista para garantia do direito à convivência familiar a todas as crianças e adolescentes. Essa lei estabelece novos prazos para a decisão judicial sobre o menor acolhido, na qual prevê que a criança sob regime de acolhimento deverá ter sua situação reavaliada a cada seis meses e sua permanência em programa de acolhimento institucional não se prolongará por mais de dois anos - salvo comprovada necessidade que atenda ao seu superior interesse, devidamente fundamentada pela autoridade judiciária.

Diante de tal reformulação, fica evidenciado o caráter estritamente temporário do acolhimento institucional. Percebemos assim, um avanço no sentido de diminuir o tempo das crianças nas instituições e garantir-lhes o direito à convivência familiar. Dessa forma, destacamos a importância de se pensar sobre este período de institucionalização, em que a criança estará temporariamente longe do convívio familiar. As relações estabelecidas nesse contexto são fundamentais para o adequado desenvolvimento psíquico e social do indivíduo.

\section{A Função dos Vínculos Afetivos no Desenvolvimento Psíquico e Social do Sujeito}

A importância dos vínculos na estruturação psíquica e social do ser humano é destacada por Winnicott (1965/2001), Bowlby (1969/2002), Ainsworth (1982), entre outros. Para esses autores, o vínculo acontece mediante o investimento afetivo e a sensibilidade materna para responder aos sinais e comunicações da criança.

Segundo Ainsworth (1982), mães que se apresentam sensíveis aos sinais e comunicações do bebê tendem a oportunizar uma segurança emocional e exploratória aos filhos; ao passo que mães emocionalmente distantes, poderão rejeitar as manifestações da criança, demonstrando irritação e impaciência na interação com ela.
Bowlby (1969/2002) descreveu a importância das primeiras relações para o desenvolvimento, formulando, desse modo, a teoria do apego, quando descreve as relações do bebê com sua mãe ou cuidador, desde o nascimento até os seis anos de idade. $\mathrm{O}$ autor enfatiza que a repetição do padrão das interações iniciais entre a mãe, ou cuidador substituto, e o bebê formará um modelo interno com o qual a criança irá estabelecer suas futuras relações. Assim, a presença de cuidados disponíveis e contingentes é essencial para a formação de um apego seguro.

Winnicott (1965/2001) destacou a condição de dependência do bebê em relação ao seu cuidador. Essa dependência é marcada por um período de experiências muito importante para a construção de um vínculo afetivo e para a constituição da personalidade da criança. Dessa forma, a mãe, ou o cuidador substituto, se apresenta como peça fundamental para elaboração dos estados emocionais da criança, o que vai influenciar na integração das suas vivências e na relação com o meio em que se insere.

A importância do vínculo afetivo na constituição da personalidade do indivíduo também é destacada por Bairros et al. (2011, p.1):

As manifestações de afeto, principalmente mãe/filho são decisivas para a formação da personalidade e terão importante influência nas relações sociais ao longo da vida, sendo assim, determinante na formação da estrutura emocional do indivíduo. Sabendo que a afetividade faz parte de todo o desenvolvimento estrutural e psicológico do ser humano, e que sem ela, este não se desenvolve plenamente, é de extrema relevância demonstrarmos a importância do afeto na construção da base da personalidade nos primeiros anos de vida, considerando que aquilo que acontece ao indivíduo neste período irá refletir-se na adolescência e na fase adulta. As impressões registradas no inconsciente, pela presença ou ausência das relações afetivas entre pais e filhos, podem causar graves transtornos afetivos e emocionais às crianças.

Nesse sentido, o vínculo afetivo apresenta-se na relação cuidador e criança como um meio de subsistência e manutenção de um ambiente adequado para o desenvolvimento sadio dessa última. Tal proximidade afetiva funciona como busca por segurança e apoio, proporcionando a capacidade funcional da personalidade da criança. A forma como são supridas suas necessidades afetivas e ambientais, e a forma como são internalizadas, pode influenciar no desenvolvimento e na capacidade de vincular-se um ao outro (Silva \& Neto, 2012).

Conforme Rygaard (como citado por Golin \& Benetti, 2013), crianças traumatizadas, abandonadas ou que não podem contar com cuidados afetivos e protetivos poderão desenvolver o transtorno de apego reativo devido às múltiplas situações de negligência a que são expostas repetidamente. Assim, quando se pensa na criança em situação de acolhimento, há de se supor que em algum momento houve uma quebra no vínculo, em especial com a mãe - quem é o primeiro objeto de amor do infante. Nesse contexto, a instituição de acolhimento surge como possibilidade de suporte material e afetivo. No entanto, para isso é necessário que os cuidadores, responsáveis pela atenção a essas crianças, estejam disponíveis para gerar, nesse ambiente, um local de 
fortalecimento e construção de vínculos saudáveis (Silva \& Neto, 2012).

Golin e Benetti (2013) citam uma pesquisa realizada por Smyke et al. com o objetivo de investigar os transtornos do comportamento de apego. Eles concluíram que o desenvolvimento emocional de crianças institucionalizadas deve ser estimulado por meio da formação de relações de apego, mesmo em ambientes institucionais. Dessa forma, de acordo com os pesquisadores, existe uma possibilidade de se diminuir o impacto da exposição a inúmeros cuidadores e, no caso de futura adoção, permitir condições mínimas para o desenvolvimento de vínculos afetivos mais estáveis.

\section{A Relação Mãe Social - Crianças e Adolescentes Acolhidos}

Winnicott (1979/2007) destacou a importância da relação mãe-criança para um desenvolvimento emocional saudável e mencionou que a ruptura do contato com a mãe é uma questão delicada e complexa. Para o autor, a substituição da família e da mãe deve ser bastante analisada, não basta apenas oferecer "outro" lar, deve-se pensar o papel da instituição de acolhimento na constituição do sujeito e refletir sobre a relação do cuidador com as crianças acolhidas. Diante desta realidade, é necessário possibilitar o estabelecimento de novos vínculos afetivos para que o desenvolvimento emocional destas crianças não esteja de todo ameaçado.

Sobre as condições necessárias ao desenvolvimento psíquico adequado, Bowlby (1973/2004) aponta para a importância de o indivíduo estar inserido em um lar saudável, ao lado de pais afetivos que deem apoio incondicional, conforto e proteção. Nesse caso, crianças em desenvolvimento podem desenvolver estruturas psíquicas seguras e fortes para o enfrentamento de dificuldades do dia-a-dia. O autor coloca também a situação inversa, ou seja, o fato de crianças crescerem em um ambiente com situações adversas que não promovam saúde e bem-estar físico e psicológico. Isso, segundo ele, pode prejudicar suas relações e seus mecanismos de enfrentamento e também trazer sequelas em fases posteriores de seu desenvolvimento.

Para tanto, os cuidados com as crianças e o fornecimento de uma base sólida e segura é essencial, principalmente quando ocorre a quebra do vínculo com a mãe. Essa situação traz angústias, além do doloroso processo de luto, que pode ser mal tolerado pela criança nessa fase do desenvolvimento (Bowlby, 1973/2004). O surgimento de novas relações na vida destas crianças é o início de um novo processo de interação social e da criação de novos vínculos, aspectos fundamentais para o seu desenvolvimento cognitivo e afetivo.

Segundo Vasconcelos, Yunes e Garcia (2009), estas interações podem influenciar a vida das crianças de maneira a inibir ou incentivar a expressão de competências na esfera cognitiva, social, afetiva e ético-moral. Neste sentido, David (como citado por Nogueira \& Costa, 2005) destaca a carência precoce observada neste contexto. De acordo com a autora, as crianças, submetidas a este tipo de sofrimento, poderão apresentar dificuldades no que se refere à constituição do self e às relações objetais. As funções cognitivas também podem ser afetadas, o que se constitui um problema dificilmente reparável.

É nesse contexto que a relação da mãe social com as crianças e adolescentes em situação de acolhimento institucional deve ser amplamente discutida, no sentido de pensar as reais possibilidades de vinculação com essa nova "mãe" que, até então, não fazia parte de seu convívio familiar e social. Na perspectiva da mãe social, é importante destacar (a) a questão da construção de vínculos passageiros, sabendo que essas crianças e adolescentes não permanecerão na casa lar por um longo período; (b) o investimento de afeto, cuidados emocionais e não apenas físicos; e (c) o exercício da função materna para com crianças e adolescentes que também não faziam parte de sua vida e que possuem particularidades em sua história pregressa, como o abandono e a violência.

Essas são questões delicadas e, ao mesmo tempo, instigantes, pois estimulam a discussão sobre uma condição, infelizmente, necessária a muitas crianças e adolescentes: o acolhimento institucional. O estudo desta temática e sua divulgação podem proporcionar uma reflexão sobre as relações estabelecidas dentro das instituições de acolhimento, estimulando ações que facilitem a convivência entre cuidadoras e os acolhidos. Assim, promovendo o desenvolvimento adequado das crianças e dos adolescentes e o bom desempenho das profissionais envolvidas nesse contexto.

\section{Método}

\section{Sujeitos e Instrumentos}

A pesquisa foi realizada por meio de um estudo de campo, de abordagem qualitativa, em quatro casas lares, situadas no interior do Estado do Paraná, no ano de 2010. Os sujeitos da pesquisa foram 4 mães sociais, 31 crianças e 5 adolescentes em situação de acolhimento institucional.

Para facilitar a especificação das casas será utilizada a designação $\mathrm{C} 1, \mathrm{C} 2, \mathrm{C} 3$ e $\mathrm{C} 4$, sendo que 4 crianças e 1 adolescente estavam acolhidos na casa $\mathrm{C} 1,8$ crianças e 1 adolescente na $\mathrm{C} 2,8$ crianças e 2 adolescentes na $\mathrm{C} 3$ e 11 crianças e 1 adolescente na $\mathrm{C} 4$. As mães sociais, que serão designadas M1, M2, M3 e M4, tinham idade acima de vinte e cinco anos e as crianças e adolescentes tinham entre cinco e dezessete anos de idade.

Os instrumentos utilizados foram a entrevista semiestruturada com as mães sociais e três observações participantes em cada casa lar, com o objetivo de obter dados sobre a relação estabelecida entre as mães sociais e as crianças e adolescentes acolhidos, enfatizando os aspectos referentes aos vínculos e a interação afetiva. Todas as entrevistas foram gravadas com o consentimento prévio das participantes e transcritas na íntegra para posterior análise. 
As observações foram redigidas pelas pesquisadoras logo após as visitas.

\section{Procedimento}

O projeto e a realização da pesquisa foram executados por alunas do $7^{\circ}$ e $8^{\circ}$ períodos do curso de psicologia de uma faculdade do interior do Estado do Paraná sob a orientação de uma professora do referido curso. Inicialmente, foi estabelecido contato com a instituição de acolhimento responsável pelas 4 casas lares e apresentado o projeto de pesquisa.

A partir da autorização da instituição de acolhimento, o projeto foi submetido junto ao Comitê de Ética responsável pelas pesquisas com seres humanos, atendendo à Resolução $n^{\circ}$ 196/96 do Conselho Nacional de Saúde. O protocolo do estudo, registrado sob $\mathrm{n}^{\circ} 415 / 2010$ obteve parecer favorável à execução da pesquisa.

O responsável pela instituição de acolhimento realizou a assinatura do Termo de Consentimento Livre e Esclarecido como responsável pelas crianças e adolescentes. Posteriormente, foram agendadas visitas as casas lares com o objetivo de apresentar o projeto também às mães sociais, que aceitaram participar, assinando o Termo de Consentimento Livre e Esclarecido. O termo menciona a questão do sigilo, da desistência em meio ao processo e da garantia de apoio psicológico aos participantes, em caso de necessidade no decorrer da pesquisa.

O primeiro passo foi a realização das entrevistas semiestruturadas com as mães sociais, que tiveram a duração de 40 minutos cada. Elas ocorreram nas dependências das casas lares, em local reservado e apropriado à realização das mesmas. As entrevistas abordaram questões relativas à relação e ao vínculo das mães sociais com as crianças e adolescentes sob seus cuidados.

Posteriormente, foram realizadas três observações participantes, em cada casa lar, com o objetivo de apreender aspectos da interação e do vínculo entre os participantes da pesquisa. Cada observação participante teve a duração média de 2 horas, totalizando a média de 6 horas de observação em cada casa lar.

\section{Análise dos Dados}

A partir do material obtido na pesquisa, foi utilizada a Análise Temática como forma de tratamento dos dados, conforme exposto por Bardin (1977). Na etapa de préanálise foi realizada uma leitura flutuante com o objetivo de apreender as impressões iniciais acerca dos dados da pesquisa. Após esse processo, foram estabelecidas duas categorias temáticas a partir de recortes do texto original. As categorias foram assim designadas: (a) $\mathrm{O}$ apego e a formação de vínculos afetivos; (b) Os cuidados físicos e afetivos.

Com isso, procedemos à etapa de tratamento dos resultados e interpretação. Essa etapa consistia na análise propriamente dita, estabelecendo as relações observadas, tanto nas entrevistas quanto nas observações, e que dizem respeito aos objetivos do trabalho; ou seja, aspectos referentes à relação entre as mães sociais e as crianças e adolescentes acolhidos, ao mesmo tempo confrontando esses dados analisados com a literatura.

\section{Resultados e Discussão}

\section{O Apego e a Formação de Vínculos Afetivos}

A teoria do apego evidencia a importância da ligação emocional que se desenvolve entre a criança e seu cuidador, para orientar o desenvolvimento afetivo, cognitivo e social dela. Bowlby (1973/2004) define o vínculo como uma ligação composta por uma rede de comportamentos que tem relação com a proteção natural da espécie. Para o autor, o vínculo afetivo entre a criança e o seu cuidador se estabelece de forma natural, dadas as devidas condições.

Bee (1997) caracteriza o apego como uma variação do vínculo afetivo, no qual existe a necessidade da presença do outro, uma sensação de segurança na presença deste. O outro é visto como uma base segura a partir da qual o indivíduo pode explorar o mundo e experimentar outras relações. Dessa forma, fica evidenciada a importância dos vínculos afetivos para o desenvolvimento psíquico e emocional do indivíduo.

Como mencionado na parte introdutória do trabalho, em situações de afastamento da criança ou do adolescente de sua família de origem, por meio de medidas protetivas em casos de violência, maus tratos ou abandono, instituições de acolhimento ficam temporariamente responsáveis pelo cuidado físico e afetivo dos mesmos, proporcionando-lhes condições necessárias ao seu desenvolvimento adequado. A pesquisa realizada buscou investigar as relações que se estabelecem neste contexto, mais especificamente entre as mães sociais e as crianças e adolescentes acolhidos. Sobre este aspecto, foram destacadas algumas colocações das mães sociais que serão apresentadas a seguir.

Quando questionada sobre a relação estabelecida com as crianças e adolescentes na casa lar, M1 coloca o seguinte:

"Eu sempre procuro ser a mãe, porque eu não sou a mãe deles, mas sempre procuro ser a mãe deles... O vínculo é muito grande... eu sempre me apego muito com eles, eu sou muito sensivel e me apego muito, muito mesmo, choro por causa deles quando estão doentes, então enfrento filas, médicos, remédios".

"Eu acho que eles são bastante afetivos, se apegam bastante com a gente, os adolescentes conversam bastante com a gente, lá fora acontece tanta coisa e eles vêm conversar com a gente".

Nos relatos de M1, fica evidenciado o apego existente na sua relação com os acolhidos. Sua vinculação afetiva com os acolhidos é confirmada no relato das pesquisadoras sobre uma das visitas realizadas: "Ao final da visita, mostrou-nos um vídeo de fotos dos acolhidos e ficou bastante emocionada ao rever alguns acolhidos que já não estavam mais na casa, disse sentir saudades".

A mãe social M2 diz na entrevista que o vínculo é materno: "Ah, o vínculo é materno né, não tem como não ser", e reconhece que é desgastante, pois queria aproveitar mais a sua família. No entanto, diz que: "ao mesmo tempo é muito 
valioso essas coisas, essas pequenas coisas", referindo-se a uma ocasião em que uma das acolhidas se aproximou dela querendo um abraço e ela, a mãe social, a abraçou.

Durante uma das observações, M2 demonstrou certa dureza ao tratar uma das crianças que havia dito preferir a "tia anterior":

A gente ouve às vezes... tem uma menininha ali que fala - ah eu gostava mais da tia A. - Daí eu falei - pois é, eu também gostava da tia A. Ela era bem gente boa, só que agora ela não tá aqui e você vai ter que engolir a esta tia, e talvez outra vez outra tia vai estar aqui, e talvez outra e outra, fazer o que, é simples. - É triste falar, mas nada é deles aqui, é muito triste, ao mesmo tempo que eles têm que se sentir seguros, a gente não pode passar essa segurança que seja uma coisa pra sempre, isso aqui não é para sempre pra eles.

No final de sua fala, menciona a questão da segurança que as crianças deveriam sentir ali e, ao mesmo tempo, sente que não pode passar essa segurança para as crianças. Demonstra, por meio do relato, certa insensibilidade e inabilidade ao lidar com as situações descritas, pois entendemos ser possível ajudar as crianças a sentirem-se mais seguras durante o tempo de acolhimento institucional. Isso demonstrando a elas que aquele é um ambiente de proteção, compreensão e carinho, enquanto encontram-se afastadas, temporariamente, do convívio familiar de origem ou substituto.

Essa mãe mencionou, também, a dificuldade que tem em lidar com os adolescentes mais velhos: "Hoje chegou um menino com treze anos, eu geralmente não me dei bem com adolescente aqui, geralmente porque meninos mais velhos são mais rebeldes, já têm autonomia pra sair, então eles pensam que podem fazem o que querem, fazer suas próprias regras e eu e o $A$. (meu esposo) não podemos deixar de jeito nenhum". Por meio dos relatos obtidos e das observações, percebemos que essa mãe social, em específico, apresentou certa dificuldade em demonstrar e perceber o afeto e os sentimentos das crianças e adolescentes acolhidos.

M3 diz que sua relação com os acolhidos é uma relação materna e descreve o vínculo como "muito forte":

"A minha relação com eles é bem tipo de mãe mesmo, a minha relação com eles é de mãe, eu não me acho e nem me sinto no lugar de tia (forma como são chamadas pelas crianças), aqui somos uma família, então eu digo pra eles que eu sou a mãe deles. Se tem alguma dificuldade na escola ou alguma coisa assim, eu digo que é pra eles se 'queixar' pra mim, a nossa relação é muito boa e a gente conversa sobre tudo mesmo. Ah o vínculo é muito forte né, é muita preocupação, como se eu fosse a mãe deles mesmo. Que nem... o dia que eles saem e demoram um pouquinho, a gente já se preocupa né, como se fosse a mãe mesmo".

No que se refere à forma como essa mãe social percebe os sentimentos dos acolhidos em relação a ela, M3 diz perceber quando gostam e quando não gostam dela. Menciona que eles se preocupam com ela quando sai e demora a chegar. E que, quando chega, eles a recebem com entusiasmo:

"Eu sinto uma coisa boa mesmo, eu sinto quando eles realmente gostam da gente e quando não gostam sabe, eles se preocupam com a gente, e eles demonstram quando eles se preocupam, sabe então você vê a preocupação com a tia, percebo que eles gostam de mim mesmo. Quando eu saio, às vezes, e chego tarde, a hora que eu chego eles vem correndo me abraçar-ah tia, ah tia".
M4 descreve a relação como "muito boa", uma relação materna. E assim como mencionado por M1, M4 também afirma sofrer quando uma das crianças sai da casa: "A relação é muito boa, é de mãe mesmo. Eu sou a que mais sofre quando alguma das crianças é adotada ou sai da casa, eu sinto muita falta deles e procuro sempre manter contato". Ela coloca que o vínculo é muito forte e que ele se construiu com o tempo, pelo afeto, amor e carinho: "O vínculo é muito forte, é de mãe e filho, eu brigo a favor deles se for preciso. Ah, o vínculo se construiu com o tempo, pelo afeto, é muito amor e carinho".

Essa mãe social disse perceber que os acolhidos a veem como sua própria mãe e que eles se sentem bem na casa lar:

"Eles me veem como mãe deles, tem criança que não quer nem ser adotada pra ficar sempre com a tia S. Eu acho que eles gostam bastante de mim, ah eles gostam de meu marido também. As crianças que estão aqui se sentem bem, a gente percebe isso, me abraçam, sentem bastante amor e carinho".

Por meio dos relatos nas entrevistas, todas as mães sociais afirmaram que o vínculo é materno, no entanto, somente M1, M3 e M4 demonstraram vincular-se afetivamente com as crianças e adolescentes acolhidos. Elas descrevem o vínculo como muito forte e relatam situações de demonstração de apego, carinho e afeto. Já M2 apresentou algumas dificuldades na relação afetiva com os acolhidos. Isso é percebido também nas observações.

As observações realizadas nas casas lares C1, C3 e C4 permitiram identificar algumas demonstrações de carinho e afeto. Na casa lar $\mathrm{C} 1$, "Um menino se aproximou da mãe social e ela demonstrou carinho com o mesmo" e em outro momento: "Elogiou bastante o menino". Na casa lar C3, "Houve demonstrações de carinho entre as crianças e a mãe social. Presenciamos um diálogo entre a mãe social e um dos meninos, e a demonstração de preocupação da mãe social em relação ao mesmo". No entanto, o que se observou foi que essa demonstração pareceu pouco genuína, como se a mãe social quisesse mostrar para as pesquisadoras que tudo estava muito bem e que sua relação com as crianças era muito boa.

$\mathrm{Na}$ casa lar $\mathrm{C} 4$, foi possível observar demonstrações de cuidado e preocupação da mãe social em relação às crianças: "A mãe social estava cuidando de um menino que estava de cama, doente e chorando. Demonstrou preocupação". Houve também demonstrações de apego: "A mãe social falou que é bem apegada às crianças e adolescentes, que quando uma é adotada sente muita falta. Demonstrou preocupação e uma saudade antecipada em relação a uma criança que seria adotada. Disse sentir falta de três irmãs que foram adotadas e guarda lembranças (fotos) das mesmas. Disse que cada criança que sai leva um pouquinho dela".

Já na casa lar C2, não houve nenhuma demonstração de carinho ou afeto entre a mãe social e as crianças e adolescentes acolhidos durante as observações participantes. Outros comportamentos foram observados nessa casa lar, como a rotulação e a exposição das crianças por parte da mãe social:

A mãe social fez comentários constrangedores de uma das crianças da casa lar na presença da mesma, dizendo que a menina não escuta, só se for gritos, e que não sabia o que era banho antes de chegar na casa lar.

A mãe social estava na cozinha olhando as crianças comerem, o seu filho biológico e uma acolhida de seis anos de idade. A 
acolhida que estava lanchando chorava de forma silenciosa, sem fazer ruido, soluçava bastante. A mãe social, juntamente com a mãe auxiliar, fizeram vários comentários a respeito da criança na presença da mesma, dizendo que ela 'não escuta' que 'é atrasada'. Enquanto ouvia, a criança chorava muito. Os comentários continuaram na frente da menina, dizendo que ela precisava de tratamento psicológico, que não era normal uma criança ser desse jeito e que a irmã dela contou que a mãe biológica surrava essa criança para ver se ela se 'espertava para a vida'e a mãe auxiliar concordava com tudo.

Os comportamentos relatados acima são descritos como componentes negativos da relação e podem prejudicar o desenvolvimento das crianças. De acordo com Selosse (citado por Lima, 2001), a rotulação pode levar a uma redução de capacidades e causar sérios danos ao desenvolvimento da criança. Para Nogueira e Costa (2005, p.14): “O respeito ao ritmo e necessidades individuais de cada um implica um olhar atento por parte do cuidador, o qual só pode ser garantido com o subsídio de muita reflexão, treinamento e preparo". Sendo assim, as questões de rotulação e exposição refletem o desrespeito e o despreparo das cuidadoras em relação ao cuidado com as crianças.

$\mathrm{Na}$ casa lar $\mathrm{C} 1$ também foram observados alguns comportamentos negativos para a relação, como os tratamentos diferenciados entre os acolhidos e os filhos ou netos biológicos, preferências entre o sexo das crianças e situações de chantagem e ameaça:

Fez chá para um dos meninos e quando ele foi fazer a refeição começou a fazer brincadeiras e a mãe social tomou o pão e o chá da mão do garoto e lançou fora, tirando o menino energicamente da mesa. Não conversou com o menino sobre a atitude do mesmo, apenas o tirou da mesa e fez o mesmo ir assistir TV na sala. Teve atitude diferenciada com um menino que estava na casa, seu neto biológico, quando o mesmo a desobedeceu, não tomou atitude semelhante a que tomou com o acolhido.

Falou que prefere somente meninos na casa, pois se relaciona melhor com meninos.

Ao chegar, falou um pouco das crianças, contou que um dos meninos ganhou um cachorrinho e que ela (M1) falou que só ficaria com o animal se o menino parasse de fazer xixi na cama.

Para Bowlby (1973/2004), a capacidade inata do ser humano para estabelecer vínculos afetivos precisa ser estimulada, adequadamente, para se concretizar. $\mathrm{O}$ vínculo precisa de manutenção adequada e estímulos pertinentes para ser satisfatório e enriquecedor na relação. Dessa forma, entendemos que os comportamentos negativos observados nas casas lares $\mathrm{C} 1$ e $\mathrm{C} 2$, como a exposição, o rótulo, o tratamento diferenciado entre os filhos ou netos biológicos e os acolhidos, as preferências entre o sexo das crianças e as situações de chantagem e ameaça, podem exercem uma influência também negativa sobre os relacionamentos e a forma de vinculação entre as mães sociais e as crianças e adolescentes acolhidos. Assim, dificultando o estabelecimento de vínculos saudáveis nesse contexto.

Algumas dificuldades no estabelecimento dos vínculos afetivos foram observadas, de forma mais nítida, na casa lar C2. Para Mondardo e Valentina (1998), os sentimentos e comportamentos da mãe em relação às crianças dependerá de suas experiências prévias, principalmente as de seu próprio ambiente familiar, com seus pais. Para os autores, as influências parentais são determinantes na forma como a mãe relaciona-se com a família atual. Assim, podemos supor que a qualidade do vínculo estabelecido entre as mães sociais e as crianças e adolescentes sob seus cuidados também será influenciada por suas vinculações pregressas.

Hecht e Silva (2005) discutem o papel dos novos vínculos afetivos como aliados para ajudar as crianças e adolescentes em situação de acolhimento institucional a enfrentar suas realidades e auxiliá-los em seu desenvolvimento. Assim, destacamos a importância da mãe social para que ocorram novas relações e novos vínculos e o processo de desenvolvimento dessas crianças não seja bruscamente interrompido. Isso supõe uma série de dificuldades que, tanto as cuidadoras quanto as crianças e os adolescentes, precisarão enfrentar para que esses vínculos e essas relações se estabeleçam efetivamente.

Nesse aspecto, Nogueira e Costa (2005) apontam a complexidade e a dificuldade de se suprirem as necessidades afetivas de crianças que passaram por alguma situação de trauma e rompimento. Isso é confirmado por Bowlby (1973/2004) quando menciona que a capacidade de estabelecimento de vínculos pode ser diminuída devido a fatores externos como as experiências de abandono, violência e maus tratos vivenciados pelas crianças e adolescentes em situação de acolhimento institucional.

A pesquisa realizada mostrou que, apesar de todas as dificuldades existentes na formação de vínculos afetivos neste contexto, os mesmos são possíveis, como demonstrado nas entrevistas e nas observações realizadas nas casas lares C1, C3 e C4 e descritas acima. Hecht e Silva (2005) destacam a disponibilidade dessas crianças para estabelecer novos vínculos. Segundo os autores, evidencia-se, num primeiro momento, uma desconfiança bastante significativa, mas respeitado o tempo de cada uma, esse temor vai-se transformando, dando lugar à credibilidade e uma gradativa confiança se estabelece.

Esses aspectos também puderam ser observados na pesquisa realizada e relatada por Rodart et al. (2015), na qual participaram seis adolescentes vitimizados e institucionalizados no Centro de Assistência à Criança e ao Adolescente Vitimizado/ Travessia (CACAV/Travessia), situado no município de Ribeirão Preto, SP, Brasil. Os resultados da pesquisa evidenciaram que os adolescentes conseguiram estabelecer vínculos de confiança com alguns funcionários, o que é considerado um fator de proteção para os mesmos. De acordo com os pesquisadores, as relações estabelecidas foram diferenciadas e mais sólidas quando o adolescente percebeu que as pessoas se preocupavam com ele, quando compartilhavam os sonhos dele e quando ele poderia, verdadeiramente, confiar nelas. Eles destacam que os adolescentes encontraram nos funcionários um meio de suprir algumas necessidades, não desenvolvidas pelos seus familiares, como afeto e diálogo. Por fim, concluem enfatizando a importância de se construir um novo olhar e uma nova escuta, proporcionando espaços de maior confiança e empatia, com condições ambientais para que as crianças e adolescentes desenvolvam suas potencialidades com maior sustentação subjetiva e social (Rodarte et al., 2015).

O trabalho realizado por Oliveira e Próchno (2010) também relata a vinculação de crianças acolhidas institucionalmente 
em relação à instituição e às cuidadoras. Nessa pesquisa, o vínculo com a instituição é descrito como algo "bom, agradável, em que as crianças atribuíram um valor de consideração pelo ambiente onde se encontram" (p.77). A relação com as atendentes, ou cuidadoras, foi descrita pelas crianças como "uma vinculação afetiva, variando de uma criança para outra" (p.77).

Nos desenhos, foram identificadas figuras de vinculação das crianças, como cuidadoras do abrigo e amigos mais próximos das crianças. (...) Figuras representativas como corações e flores apareceram principalmente nos desenhos das meninas e referiam-se a pessoas queridas da instituição, configurando um contexto de afetividade expressado por elas. (Oliveira \& Próchno, 2010, p.78)

Esses trabalhos, assim como a presente pesquisa, evidenciam a possibilidade e a necessidade da construção de vínculos afetivos no contexto de acolhimento institucional. Entendemos, no entanto, que os cuidados dedicados a essas crianças e a forma como ocorrem as interações nesse contexto, irão exercer uma influência significativa no surgimento da confiança e da abertura para o vínculo. Por isso, passaremos agora à exposição dos resultados referentes aos cuidados e à forma de interação entre os participantes da pesquisa.

\section{Os Cuidados Físicos e Afetivos}

Segundo Bowlby (1973/2004), a criança não é um ser capaz de desenvolver-se sozinha, necessita de uma instituição social para crescer e tornar-se madura. Portanto, o papel da família é importantíssimo para estruturação desse ser e, na ausência desta, a instituição de acolhimento passa a assumir esse papel. O autor elenca duas funções básicas destas instituições: primeiramente, a satisfação de necessidades básicas como alimentação, calor, abrigo e proteção; e, em segundo lugar, não menos importante, um ambiente no qual a criança possa desenvolver, ao máximo, suas capacidades físicas, mentais e sociais.

A seguir, foram apresentados trechos das entrevistas com as mães sociais que retratam os cuidados e a interação das mesmas com as crianças e adolescentes acolhidos:

Arrumo as crianças para ir para a escola. Tem os afazeres da casa... todos ajudam, os maiores ajudam bastante. A gente conversa bastante à noite quando estamos todos juntos... (M1) Ah é uma rotina né, uma rotina como em uma casa, tem horário de acordar, horário de café da manhã, tem crianças que estudam na parte da manhã, tem crianças que estudam na parte da tarde, o almoço é pontualmente nos dias de semana ao meio dia, agora a gente está com crianças menores e geralmente a gente dá almoço antes porque eles precisam de ajuda nossa para se alimentar. Mas é uma rotina, com trabalhos da casa, limpeza... tem responsabilidades... limpeza de tapetes, dos vidros, uma vez por semana, lavamos cobertores juntos. Semana passada, foram tirados dois de cada quarto, coisas que tem que ser feita como uma casa normal, (M2)

"A atividade nossa aqui é o trabalho" (M3). Ela menciona também que conversa muito com as crianças e o adolescente: "Eu converso muito com eles, a gente tem que conversar pra poder se entender, né?".
A gente levanta, arruma a cama, escova os dentes, faz um café, e as meninas maiores, me ajudam. (M4)

As falas apresentadas demonstram uma grande preocupação das mães sociais no que se refere aos cuidados físicos com as crianças e adolescentes, como a higiene e a alimentação, o cuidado em arrumá-las para irem à escola, também uma preocupação com os horários e a rotina da casa de uma forma geral. Cuidados afetivos, como demonstrações de carinho e atenção, foram apresentados em algumas ocasiões. As mães sociais relataram que conversavam bastante com as crianças e adolescentes. Os cuidados afetivos também foram apresentados em alguns momentos de demonstração de carinho e preocupação das mães sociais em relação aos acolhidos, situações essas já descritas anteriormente. Porém, de uma forma geral, os cuidados observados, predominantemente, foram os cuidados físicos e a preocupação com as atividades domésticas.

Isso foi observado com mais ênfase na casa lar C2. É possível perceber na fala de M2 grande ênfase aos cuidados domésticos, como a limpeza e a organização da casa. Logicamente, esses são aspectos importantes, mas, quando realizados de forma excessiva, podem prejudicar a interação entre a mãe social e os acolhidos.

A partir das entrevistas e das observações realizadas na pesquisa, pôde-se perceber que a relação estabelecida nesta casa lar, especificamente, concretiza-se na execução de atividades domésticas e no cuidado físico das crianças. Essa mãe social apresentou cuidados de higiene extremamente rigorosos, dizendo-se rígida e severa em algumas situações. Coincidentemente ou não, essa também foi a casa em que menos se percebeu demonstrações de afeto e carinho em relação aos acolhidos.

Sobre esse aspecto podemos dizer que os cuidados físicos são garantias legais a todas as crianças e adolescentes (Lei 8.069, 1990). No entanto, de acordo com Faquinello e Collet (2003), os cuidados emocionais e psicológicos são tão importantes quanto os cuidados físicos para aqueles que estão em fase de desenvolvimento. Dessa forma, é importante discutir o papel da mãe social na vida das crianças e adolescentes sob seus cuidados. De acordo com a Lei $\mathrm{n}^{\circ} 7.644$ de 18 de dezembro de 1987, caberá a mãe social oferecer proteção, carinho, segurança, cuidados físicos e emocionais, entre outros aspectos constituintes dessa relação.

Segundo Santos ( citado por Alexandre \& Vieira, 2004), para que haja cuidados satisfatórios para os acolhidos, o princípio norteador dos cuidadores deve ser o de oferecer as condições necessárias para o seu pleno desenvolvimento, tanto nas questões físicas como psíquicas. Hecht e Silva (2005) colocam que o ser humano, na sua essência, necessita de cuidados, inclusive cuidados afetivos que sejam traduzidos em forma de proteção e segurança. Esses são fatores importantes para o bom desenvolvimento emocional e cognitivo da criança.

Sobre isso, Nogueira e Costa (2005) mencionam que a rotina das instituições de acolhimento, inclusive os cuidados excessivos com a limpeza, são questões típicas institucionais, demonstrando profissionais despreparados para os cuidados com os acolhidos. De acordo com os autores, essas instituições, em sua maioria, não parecem considerar a individualidade e as necessidades de cada criança. Não são 
oferecidas às mães sociais nem a preparação adequada nem as condições necessárias para o desempenho da função; de forma que, no seu dia a dia, não dividem o tempo visando atender às crianças e aos adolescentes. Extremamente preocupadas com a limpeza e a organização da casa, não encontram tempo para outras atividades que proporcionem o estabelecimento de vínculos afetivos e envolvimento emocional.

Percebemos que as formas de interação e os cuidados físicos e afetivos das mães sociais, em relação às crianças e aos adolescentes sob seus cuidados, são fundamentais na formação dos vínculos afetivos. No entanto, é relevante incluir, nesta discussão, outros aspectos específicos e relevantes dessa relação e que podem exercer, também, sua influência na formação dos vínculos.

Parreira e Justo (2005) ressaltam a dificuldade na criação de vínculos dentro das instituições de acolhimento, chamando a atenção para o caráter temporário do acolhimento institucional. Para os autores, estar em situação de acolhimento institucional significa, muitas vezes, lidar com as facetas do abandono e da falta de referenciais. Assim, ao se analisar a questão dos vínculos afetivos neste contexto, devese considerar o fato de que as crianças que lá se encontram, mais cedo ou mais tarde, retornarão às suas famílias de origem ou serão adotadas. A função da instituição, nesse sentido e, mais precisamente, da cuidadora ou mãe social deve ser a de ajudar a criança a se preparar para o momento da partida.

Pensando por este viés, pode-se questionar como fica, para as mães sociais, a necessidade de realizarem seu trabalho de cuidadoras, tendo de vincular-se afetivamente aos acolhidos e, ao mesmo tempo, estar preparadas para que estes "filhos sociais", sem muitos avisos, hora ou outra, sejam tirados delas. Essa não nos parece uma condição muito confortável, pois envolve uma exigência de investimento de afeto e carinho direcionados a um vínculo extremamente temporário.

Para algumas mães sociais, isso pode até mesmo ser a fonte de resistências na criação de vínculos afetivos com os acolhidos, talvez para elas seja mais confortável evitar o sofrimento da separação. Esses, sem dúvida, são aspectos bastante complexos, mas que precisam ser pensados e analisados à luz das necessidades apresentadas pelas crianças e adolescentes em situação de acolhimento institucional.

Dessa forma, entendemos que o afeto e o vínculo que podem ou não se estabelecer entre as mães sociais e as crianças e adolescentes sob seus cuidados estão condicionados a inúmeros fatores. Entre eles, podemos destacar disponibilidade afetiva para o vínculo, decorrente da história pregressa das cuidadoras e dos acolhidos, bem como de toda a preparação e acompanhamento necessários ao bom desenvolvimento dessa tão complexa e importante função: ser mãe social.

\section{Considerações Finais}

Por meio do estudo realizado, percebemos que, apesar das dificuldades no estabelecimento de vínculos afetivos no contexto de acolhimento institucional, eles são possíveis, desde que haja disponibilidade para o contato afetivo e para lidar com as incertezas inerentes a esse contexto. Isso foi observado, mais especificamente, nas casas lares C1, C3 e $\mathrm{C} 4$, nas quais houve demonstrações de afeto e apego entre os participantes da pesquisa.

As dificuldades na vinculação apareceram, de forma mais nítida, na casa lar C2. A esse respeito, é importante considerar vários aspectos. De acordo com Hecht e Silva (2005), há o fato de que a instituição se preocupa em atender as necessidades básicas ao desenvolvimento das crianças. Assim, tende a apresentar dificuldades em oferecer um atendimento mais individualizado, no qual se estabeleçam laços afetivos consistentes e se valorizem as necessidades afetivas de cada criança ou adolescente.

Foi possível perceber, de forma geral, certo despreparo das mães sociais para o desempenho da função, como nas situações de exposição e rotulação, por exemplo. Mas as dificuldades encontradas não se referem apenas a essas situações, existe, também, a dificuldade de interação com as crianças. Isso devido à sobrecarga de atividades domésticas e uma ênfase excessiva nos cuidados físicos, em detrimento dos cuidados afetivos.

Assim, ressaltamos as condições que são oferecidas a essas mães sociais para o desempenho de sua função, bem como a necessidade de preparação e capacitação dessas mulheres para lidar com a realidade dos acolhidos, respeitar sua individualidade e perceber suas necessidades. É importante pensar até mesmo na forma como as mães sociais são selecionadas para o exercício da função.

Deve ser destacada, também, a necessidade de acompanhamento contínuo junto às mães sociais, em que sejam trabalhadas as questões psicológicas relacionadas ao desempenho da função. Como mencionado no trabalho, as experiências anteriores vivenciadas na própria família podem influenciar a forma como essas profissionais reagirão em determinadas situações na relação com os acolhidos. Além disso, terão que, frequentemente, lidar com o apego e a separação, aspectos que requerem constante reflexão e elaboração emocional.

Levantamos como possibilidade a criação de grupos de apoio psicológico a essas mulheres; a construção de um espaço no qual elas possam falar de seus problemas, construir e desconstruir seus papéis sociais, trocar experiências e, assim, talvez efetivar uma prática profissional mais adequada e menos sofrida tanto para elas quanto para os acolhidos. Esses grupos deveriam ser permanentes e envolver tanto pessoas que já exerçam essa função quanto pessoas que pretendem exercê-la.

Um fato também identificado durante o estudo foi a escassez de atividades interativas entre as mães sociais e os acolhidos. As atividades realizadas são, predominantemente, domésticas. Não foram mencionados momentos de descontração, lazer, brincadeiras e interação entre os participantes da pesquisa. Dessa forma, sugere-se a implementação desses recursos de aproximação lúdica nas casas lares. Recursos esses que podem facilitar a formação dos vínculos afetivos e fortalecer as relações estabelecidas nesse contexto.

Quando Nogueira e Costa (2005) mencionam o aforismo "a mãe cuida porque ama, a profissional ama porque cuida", 
estão apontando para o fato de que, por meio do cuidado, ligações afetivas podem surgir. Assim, a vinculação afetiva esperada e necessária no contexto de acolhimento institucional torna-se possível; desde que condições favoráveis, internas e externas aos envolvidos na relação, e discutidas nesse estudo, estejam presentes.

$\mathrm{O}$ estudo permitiu a investigação dos aspectos referentes à relação das mães sociais e as crianças e adolescentes acolhidos, especificamente os relacionados à vinculação afetiva. É necessário, no entanto, que novas pesquisas sejam realizadas no intuito de aprofundar essa problemática e fornecer novas contribuições sobre o tema.

\section{Referências}

Ainsworth, M. D. (1982). Attachment: retrospect and prospect. In C. M. Parkes \& J. S. Hinde (Eds.), The place of attachment in human behavior (pp. 03-30). Nova York: Basic Books.

Alexandre, D. T., \& Vieira, M. L. (2004). Relação de apego entre crianças institucionalizadas que vivem em situação de abrigo. Psicologia em Estudo, 9(2), 207-217. Retirado de http://www. scielo.br/pdf/pe/v9n2/v9n2a07.pdf

Bairros, J., Belz, C.W., Moura, M., Oliveira, S. G., Rodrigues,T. T., Silva, S. C., \& Costa, F. T. (2011). Infância e adolescência: A importância da relação afetiva na formação e desenvolvimento emocional (XVI Seminário Interinstitucional de Ensino, Pesquisa e Extensão). Universidade de Cruz Alta, Cruz Alta, RS, Brasil. Retirado de http:/www.unicruz.edu.br/seminario/artigos/humanas/ INF $\%$ C3 $\% 82$ NCIA $\% 20 \mathrm{E} \% 20$ ADOLESC $\%$ C3\%8ANCIA $\% 20$ A $\% 20$ I M P O R T \% C $3 \% 82$ N C I A \% 20 D A \% 20 RELA $\% \mathrm{C} 3 \% 87 \% \mathrm{C} 3 \% 83 \mathrm{O} \% 20 \mathrm{AF}$

Bardin, L. (1977). Análise de conteúdo. Lisboa: Edições 70.

Bee, H. (1997). O Ciclo Vital. Porto Alegre: Artes Médicas.

Bowlby, J. (2002). Apego: A natureza do vínculo. São Paulo: Martins Fontes. (Originalmente publicado em 1969).

Bowlby, J. (2004). Teoria do apego e perda. São Paulo: Martins Fontes. (Originalmente publicado em 1973).

Faquinello, P., \& Collet, N. (2003). Vínculo afetivo mãe/criança na unidade de alojamento conjunto pediátrico. Revista Gaúcha de Enfermagem, 24(3), 294-304. Retirado de http://seer. ufrgs.br/index.php/RevistaGauchadeEnfermagem/article/ viewFile/4462/2400

Ferreira, E. O., Francischini, R., \& Patiño, J. F. (2008). Crianças em situação de abrigo - casas lares: os vínculos e a composição do espaço sob o olhar das crianças. Núcleo de Estudos Socioculturais da Infância e Adolescência - Departamento de Psicologia, Universidade Federal do Rio Grande do Norte, Natal, RN, Brasil. Retirado de http://www.consec.rn.gov. $\mathrm{br} /$ contentproducao/aplicacao/consec/arquivos/enviados/ crian $\%$ C3\%A7as $\% 20 \mathrm{em} \% 20$ situa $\% \mathrm{C} 3 \%$ A7\%C3\%A3o $\% 20$ de\%20abrigo.pdf

Golin, G., \& Benetti, S. P. C. (2013). Acolhimento precoce e o vínculo na institucionalização. Psicologia: Teoria e Pesquisa, 29(3), 241-248. Retirado de http://www.scielo.br/pdf/ptp/ v29n3/v29n3a01.pdf
Hecht, B., \& Silva, R. F. P. (2009). Crianças institucionalizadas: A construção psíquica a partir da privação do vínculo materno (Trabalho de Conclusão de Curso de Graduação em Psicologia). Pontifícia Universidade Católica do Rio Grande do Sul, Porto Alegre, RS, Brasil. Retirado de http://www.psicologia.com.pt/ artigos/textos/TL0199.pdf

Lei n. 7.644, de 18 de dezembro de 1987. (1987). Dispõe sobre a regulamentação da atividade de mãe social e dá outras providências. Diário Oficial da União. Brasília, DF. Retirado de http://www.dji.com.br/leis_ordinari as/1987-007644/1987-007644-.htm

Lei n. 8.069, de 13 de julho de 1990. (1990). Dispõe sobre o Estatuto da Criança e do Adolescente e dá outras providências. Presidência da República. Brasília, DF. Retirado de http:// www.planalto.gov.br/ccivil_03/leis/18069.htm

Lei n. 12.010, de 3 de agosto de 2009. (2009). Dispõe sobre adoção. Presidência da República. Brasília, DF. Retirado de http://www. planalto.gov.br/ccivil_03/_ato2007-2010/2009/lei/112010.htm

Lima, R. C. P. (2001). Sociologia do desvio e interacionismo. Tempo Social, 13(1), 185-201. Retirado de http://www.scielo.br/pdf/ ts/v13n1/v13n1a12.pdf

Mondardo, A. H., \& Valentina, D. D. (1998). Psicoterapia infantil: Ilustrando a importância do vínculo materno para o desenvolvimento da criança. Psicologia: Reflexão e Crítica, 11(3), 621-630. Retirado de http://www.scielo.br/scielo. php?script=sci_arttext\&pid=S0102-79721998000300018\&ln $\mathrm{g}=\mathrm{en} \& \mathrm{t} \operatorname{lng}=\mathrm{pt}$

Nogueira, P. C., \& Costa, L. F. (2005). Mãe social: Profissão? Função materna?. Estilos da Clínica, 10(19), 162-181. Retirado de http://pepsic.bvsalud.org/scielo.php?pid=S1415$71282005000200010 \&$ script $=$ sci_arttext

Oliveira, S. V., \& Próchno, C. C. S. C. (2010). A vinculação afetiva para crianças institucionalizadas à espera de adoção. Psicologia Ciência e Profissão, 30(1), 62-84. Retirado de http://www.scielo.br/scielo.php?script=sci_arttext\&pid $=$ S1414-98932010000100006

Parreira, S. M. C. P., \& Justo, J. S. (2005). A criança abrigada: considerações acerca do sentido da filiação. Psicologia em Estudo, 10(2), 175-180. Retirado de http://www.scielo.br/pdf/ $\mathrm{pe} / \mathrm{v} 10 \mathrm{n} 2 / \mathrm{v} 10 \mathrm{n} 2 \mathrm{a} 03 . \mathrm{pdf}$

Resolução $n^{\circ} 196 / 96$ de 2012. (2012). Comissão Nacional de Ética em Pesquisa. Conselho Nacional de Saúde. Ministério da saúde. Retirado de http://conselho.saude.gov. $\mathrm{br} /$ Web_comissoes/conep/aquivos/resolucoes/23 out_versao final 196_ENCEP2012.pdf

Rodarte, B. C., Carlos, D. M., Leite, J. T., Beserra, M. A., Oliveira, V. G., \& Ferriani, M. G. C. (2015). Fatores de proteção sob o olhar de adolescentes vitimizados e institucionalizados. Revista de Enfermagem Referência, 4(7), 73-80. Retirado de http://www.scielo.mec.pt/scielo.php?script=sci_arttext\&pid $=$ S0874-02832015000700008

Schogor, W. L. C. (2003). Um olhar simbólico sobre a casa lar: Veneno e remédio (Monografia Especialização em Psicologia Analítica). Pontifícia Universidade Católica do Paraná, Curitiba, PR, Brasil. Retirado de http://www.symbolom.com. $\mathrm{br} /$ monografias/veneno-e-remedio.doc. 
Silva, E. R. A., \& Aquino, L. M. C. (2005). Os abrigos para crianças e adolescentes e o direito à convivência familiar e comunitária. Politicas Sociais - Acompanhamento e Análise, 11, 186-193. Retirado de http://www.ipea.gov.br/sites/000/2/publicacoes/ bpsociais/bps_11/ENSAIO3_Enid.pdf

Silva, M. R. C., \& Neto, Z. G. S. (2012). Perspectiva psicanalítica do vínculo afetivo: O cuidador na relação com a criança em situação de acolhimento (Trabalho de Conclusão de Curso de Psicologia). Instituto Luterano de Ensino Superior de Porto Velho, Porto Velho, RO, Brasil.
Vasconcelos, Q. A., Yunes, M. A. M., \& Garcia, N. M. (2009). Um estudo ecológico sobre as interações da família com o abrigo. Paidéia, 19(43), 221-229. Retirado de http://www.scielo.br/ scielo.php?script=sci_arttext\&pid=S0103863X20090002000 $10 \& \operatorname{lng}=\mathrm{pt} \& \mathrm{nrm}=\mathrm{iso}$

Winnicott, D. (2001). A familia e o desenvolvimento individual. São Paulo: Martins Fontes. (Originalmente publicado em 1965).

Winnicott, D. (2007). O ambiente e os processos de maturação: Estudos sobre a teoria do desenvolvimento emocional. Porto Alegre: Artmed. (Originalmente publicado em 1979).

Recebido em 31.12.2013

Primeira decisão editorial em 07.12.2016

Versão final em 06.04.2017

Aceito em 06.04.2017 